\title{
The value of investigation for genetic counselling in tuberous sclerosis
}

\author{
A E Fryer, A H Chalmers, J P Osborne
}

\begin{abstract}
Forty sets of parents and 24 sibs of patients with tuberous sclerosis were investigated by an extensive protocol, including clinical examination of skin, hair, and oral cavity, direct and indirect ophthalmoscopy, cranial CT scan, renal ultrasound, and a radiological skeletal survey. None of the clinical examinations provided evidence that any of the subjects was affected. Similarly, the cranial CT scan, renal ultrasound, and skeletal survey failed to identify any occult gene carriers. All of these investigations showed abnormalities in some parents but none was diagnostic. This study shows the difficulties in interpretation that these investigations may produce with consequent problems for genetic counselling. The study does not support the routine use of these tests. There are published reports where the diagnosis of tuberous sclerosis has been made in adults exclusively on a CT scan and an argument can be made for including this investigation. There is no indication for performing renal ultrasound nor skeletal $x$ rays in parents who have normal clinical examinations.
\end{abstract}

Tuberous sclerosis (TS) is a serious single gene disorder characterised by multiple hamartoma formation. It is best known for causing mental retardation and fits and at the beginning of this century this combination, along with facial angiofibromas, constituted the classical clinical triad of Vogt. ${ }^{2}$ Subsequently it has become clear that affected subjects

Bath Unit for Research into Paediatrics, Royal United Hospital, Bath.

A E Fryer, J P Osborne

Department of Radiology, Royal United Hospital, Bath. A H Chalmers

Correspondence to Dr Fryer, Institute of Medical Genetics, University Hospital of Wales, Heath Park, Cardiff CF4 4XW.

Received for publication 18 May 1989

Revised version accepted for publication 27 September 1989. need not have all or indeed any of these manifestations. The diagnosis in these subjects has been established on the basis of other features of the disorder, as shown in table 1 , and diagnostic criteria have been suggested. ${ }^{2}$ Autosomal dominant inheritance is well established but in all series the majority of patients are reported to be new mutants. In the study of Bundey and Evans, ${ }^{3}$ 71 families were assessed by interview and skin examination and the percentage of sporadic cases was $84 \%$. An American study by Lagos and Gomez, ${ }^{4}$ also of 71 families, involved interview and skin and eye examinations, and found that $73 \%$ of the cases were sporadic. There are occasional reports of families where clinically normal parents have had more than

Table 1 The major clinical and radiological abnormalities of tuberous sclerosis and their reported frequencies.

\begin{tabular}{|c|c|}
\hline $\begin{array}{l}\text { Cutaneous } \\
\text { Facial angiofibromas } \\
\text { Hypopigmented macules } \\
\text { Shagreen patch } \\
\text { Ungual fibromas } \\
\text { Forehead plaque }\end{array}$ & $\begin{array}{r}40-90 \% \\
80-90 \% \\
20-40 \% \\
15-50 \% \\
25 \%\end{array}$ \\
\hline $\begin{array}{l}\text { Neurological } \\
\text { Seizures } \\
\text { Mental retardation } \\
\text { Giant cell astrocytomas }\end{array}$ & $\begin{array}{r}85 \% \\
50-60 \% \\
5-10 \%\end{array}$ \\
\hline $\begin{array}{l}\text { Cranial CT scan findings } \\
\text { Subependymal nodules } \\
\text { Cortical lesions } \\
\text { (either calcified or } \\
\text { low density) }\end{array}$ & $\begin{array}{l}90 \% \\
50 \%\end{array}$ \\
\hline $\begin{array}{l}\text { Renal } \\
\text { Angiomyolipomas } \\
\text { Cysts }\end{array}$ & $\begin{array}{l}60 \% \\
20 \%\end{array}$ \\
\hline $\begin{array}{l}\text { Cardiac } \\
\text { Rhabdomyomas }\end{array}$ & $50-60 \%$ \\
\hline $\begin{array}{l}\text { Skeletal } \\
\text { Sclerotic patches } \\
\text { Pseudocysts } \\
\text { Periosteal new bone }\end{array}$ & $\begin{array}{l}60 \% \\
60 \% \\
60 \%\end{array}$ \\
\hline $\begin{array}{l}\text { Others } \\
\text { Poliosis } \\
\text { Gum fibromas } \\
\text { Dental pits }\end{array}$ & $\begin{array}{l}20 \% \\
10 \% \\
70 \%\end{array}$ \\
\hline $\begin{array}{l}\text { Pulmonary } \\
\text { Honeycomb lung }\end{array}$ & Rare \\
\hline
\end{tabular}


one affected child ${ }^{5}$ and Murphy et $a l^{6}$ reported a family where the mother of an affected child had no clinical signs but subependymal calcification on a CT scan. Three studies have evaluated family members by thorough investigation, including CT scanning. Fleury $e t a l^{7}$ looked at both parents of 48 children with TS in the Netherlands and included a CT scan in their protocol. They found evidence of disease in 21 parents (that is, familial cases $44 \%$, new mutants $56 \%$ ). It is of interest that in none of the parents did CT scan abnormalities occur without skin manifestations. In four of the parents the only abnormalities were ophthalmological. Cassidy et al looked at the parents of 13 families in which the affected child had been regarded as a new mutant. Evidence of the disease was found in four parents. In three of these, skin signs were present but in one the diagnosis was based on radiological signs only (positive cranial CT scan, renal ultrasound, and hand $x$ rays). They concluded that parents of TS patients should be evaluated by a protocol that includes skin examination, eye examination through dilated pupils, cranial CT scan, and renal imaging. More recently, Flinter and Neville ${ }^{9}$ have reported their experience in 13 families seen at Guy's Hospital, London. Of eight families with one affected chiid, four patients were found to be affected, two on the basis of cranial CT findings alone.

The extent to which parents are investigated varies from centre to centre, and is an area of difficulty in genetic counselling. Some counsellors rely on clinical examination alone, others also include a CT scan, and some follow the protocol of Cassidy $e t a l^{8}$ and include renal imaging and hand $x$ rays. The studies of Cassidy et $a l^{8}$ and Flinter and Neville ${ }^{9}$ suggest that cranial CT scanning should be an integral part of this assessment, but the study of Fleury et $a l^{7}$ and the large Bundey and Evans survey ${ }^{3}$ (where there were no families with clinically normal parents and more than one affected child) would suggest that this approach would detect very few unrecognised cases. We have therefore sought to investigate this problem by evaluating 40 families who have one or more children with TS, but where neither parent after clinical examination was thought to be affected.

\section{Methods}

Forty families suitable for this study were sought from clinicians and through the Tuberous Sclerosis Association (TSA). Families were recruited where the affected child was thought to represent a new mutation. Seventeen apparently normal children of affected parents were examined as part of our linkage study ${ }^{10}$ and seven sibs of sporadic cases were examined after a request for genetic advice.

All families were initially contacted by letter and then arrangements made for a home visit, during which the study was explained in detail and written consent obtained. It was usually possible to meet the proband during the home visit and confirm the diagnosis, according to the Gomez criteria. A family history was then taken with particular reference to a history of seizures, mental retardation, and suggestive skin lesions. It was also possible during these home visits to perform skin and eye examinations on parents, sibs, grandparents, and other relatives if available.

A standard protocol for the assessment of all parents and some adult sibs was drawn up. This involved the following.

\section{CLINICAL EXAMINATION}

\section{Skin examination}

A careful search was made for facial angiofibromas, forehead plaques, shagreen patches, ungual fibromas, grooving and ridging of the nails, and depigmented patches of skin and hair. The skin examination was completed with an examination in a darkened room using a powerful UV lamp to detect hypopigmented macules.

The hair was examined for streaks of white or grey hair. These were only regarded as significant if they had been present since early childhood.

\section{Oral cavity}

The gums were examined for the presence of fibromas and naked eye examination of the teeth for pits was performed.

\section{Eye examination}

This was performed using direct and indirect ophthalmoscopy through dilated pupils. Both pupils were dilated with one drop of $0.5 \%$ tropicamide. Indirect ophthalmoscopy was performed using a portable ophthalmoscope.

\section{SPECIAL INVESTIGATIONS \\ Renal ultrasound examination}

These were performed by AEF within the $X$ ray Department at the Royal United Hospital, Bath, using an ATL 100 mechanical sector scanner with a $3.5 \mathrm{MHz}$ probe. Both kidneys were visualised and a search made in longitudinal and cross sectional planes for both echodense tumours (which are characteristic of angiomyolipomas) and for cysts. A cyst had to fulfil the criteria of being rounded, trans-sonic, and with bright echoes beyond.

Skeletal $x$ rays

Radiographs were taken of the chest, hands, feet, and 
long bones. Most of the pelvis, including the ilia, was included on the views of the upper femur.

\section{Computed cranial tomography}

In those families where this had not already been performed, examinations were performed on a Somatom DR CT scanner. No contrast medium was given.

All subjects were over 18 years of age and the study was approved by the local ethical committee. All $x$ rays were ascribed a number and then reported blind by a Consultant Radiologist (AHC) at the Royal United Hospital, Bath. Abnormalities reported by AHC were reviewed with him by JPO and AEF.

\section{Results}

Forty families were studied and of these 16 lived in the Bath and Bristol health districts, 11 in other parts of the south-west region, nine in other parts of Wessex, two in South Wales, and one each in the Brighton and Nottingham health districts. Two families had two affected children, but neither parent had diagnostic evidence of TS on clinical examination. In several of the families there was a history of a distant relative with seizures, mental retardation, or white patches of skin or hair, but in no family did the history strongly suggest that any of these relatives had TS.

\section{CLINICALLY NORMAL PARENTS}

No family was excluded from the study because of the unexpected finding of clinical evidence of the disease on skin or ophthalmological examination of the parents.

\section{Cranial CT scanning}

None of the cranial CT scans showed diagnostic abnormalities. In 70 cases the scans were normal. A large number of scans showed both pineal gland and choroid plexus calcification, which is normal in adults. Three scans showed spots of calcification elsewhere, but none of these was in sites typical of TS. In one case, calcification was present in the pineal recess and, in a second case, two tiny flecks of calcification were noted in the midbrain. In the third case, cerebellar gyral calcification was observed in a man of 70 years.

One cranial CT scan showed considerable cerebral atrophy for a woman in her thirties. This woman had no clinical evidence of cerebral impairment and no history of any cerebral insult.

\section{Renal ultrasound examination}

This investigation proved unrewarding. Possible cystic areas in the left kidney were noted in one parent, but this appearance was not verified on CT scanning. The reason for this ultrasound appearance remains obscure.

\section{Skeletal survey}

Sixty-five of the skeletal surveys were either normal or showed unrelated abnormalities. Sclerotic areas of bone were observed in 13 surveys and seven of these had the appearance of bone islands. Bone islands are typically smooth, rounded densities, most frequently seen in the long bones. Six surveys showed sclerotic areas that were not typical of bone islands. These observed lesions were single (except in one case with two lesions) and were found in the hands. None of them was in the typical sites reported in TS, that is, the spine and pelvis. None was associated with pseudocysts or periosteal new bone formation. Three surveys showed lucent areas in the bone as the sole abnormality. One consisted of small lucencies in the midshafts of the second and third metacarpals of the left hand. The lesions were not as well demarcated as the pseudocysts reported in TS and were not associated with any periosteal new bone formation. The second had a clearly defined lucent area in the proximal phalanx of the right thumb and the third had a less clearly defined lucent area in the right humerus. No other skeletal abnormalities were present.

With the assistance of Dr MacKenzie-Cook, Consultant Radiologist, a separate survey was performed of 93 consecutive hand $x$ rays from adults seen in the Accident and Emergency Department at the Royal United Hospital, Bath. Of these, six had sclerotic lesions present. All these were smooth and round and were typical bone islands.

The results of the parents' survey are summarised in table 2. Two parents had abnormalities reported on both a cranial CT scan and a skeletal survey. One of these (the father of two affected children) had minimal ventricular dilatation on cranial CT scan and a sclerotic lesion of a first metacarpal on hand $x$ ray. The other subject, the parent of one affected child, had marked cortical atrophy on CT scan for a person of 30 years of age, and several poorly demarcated lucencies in the second and third metacarpals on hand $x$ ray.

Table 2 A summary of the findings on the radiological examination of the 80 parents. The renal ultrasounds were normal.

\begin{tabular}{lc}
\hline & No of subjects \\
\hline Normal & 57 \\
Cranial CT scan anomalies only & 8 \\
Skeletal $x$ ray anomalies only & 13 \\
Both cranial CT and skeletal anomalies & $2^{*}$
\end{tabular}

*One of these parents had two affected children. 


\section{SIBS WITH AFFECTED PARENTS}

Seventeen offspring were unaffected on clinical examination and had an affected parent (that is, a $50 \%$ prior risk). The clinical histories of all these subjects were reviewed and these proved unremarkable in 15 of them. In one subject, there was a poorly documented history of a single seizure in childhood and a history of behavioural difficulties. His parents had always found him more 'difficult' than his two older sibs, being uncooperative and quick tempered. He volunteered a history of solvent abuse. One other subject gave a history of a possible single seizure in adult life.

\section{Cranial CT scanning}

In 15 of the 17 cases, the scans were normal. Two scans showed isolated hypodense lesions. The first of these had a small lesion in the right and left external capsules respectively.

\section{Renal ultrasound examination}

This was completely normal in 16 subjects. In one subject, a single cyst of the right kidney was found. This person was 40 years of age at the time of the scan. She had a normal cranial CT scan.

\section{Skeletal survey}

None of the surveys showed diagnostic abnormalities. Bone islands were reported in three surveys and were multiple in all cases. One subject had a sclerotic lesion which could not be termed a bone island as previously described. This lesion was small and elongated and present in the proximal phalanx of the left middle finger.

\section{SIBS WITH UNAFFECTED PARENTS}

Seven subjects were sibs of TS patients, but had parents who were clinically normal (that is, a low prior risk). None of these seven had any relevant symptoms in their histories.

\section{Cranial CT scanning}

Two scans showed cerebral calcification. One subject, aged 17 years, had calcification in the falx cerebri. The other scan showing cerebral calcification was on a 39 year old woman, tiny flecks of calcification being present in the caudate nuclei, none of which was abutting onto the ventricular surface.

\section{Renal ultrasound examination}

All the seven subjects had normal renal ultrasound examinations.
Table 3 A summary of findings on the radiological and ultrasound examinations of sibs of TS patients.

\begin{tabular}{lcc}
\hline & \multicolumn{2}{c}{ No of sibs } \\
\cline { 2 - 3 } & $\begin{array}{c}\text { At } 50 \% \\
\text { prior risk }\end{array}$ & $\begin{array}{c}\text { At low } \\
\text { prior risk }\end{array}$ \\
\hline No abnormalities & 13 & 4 \\
Cranial CT anomalies only & 2 & 2 \\
Renal US anomalies only & 1 & 0 \\
Skeletal anomalies only & 1 & 1 \\
Both CT and skeletal anomalies & 0 & 0 \\
\hline
\end{tabular}

\section{Skeletal survey}

No diagnostic abnormalities were found. One subject had a sclerotic lesion. The results of the survey of sibs are summarised in table 3 .

\section{Discussion}

The aim of this study was to investigate 40 families where neither parent was thought to be a gene carrier. The protocol included a re-evaluation of the clinical features (including the family history) and a thorough radiological assessment involving a cranial CT scan, renal ultrasound, and skeletal survey. In selecting the 40 families, no family had to be excluded because of the finding of diagnostic clinical signs, which suggests that the parents had been properly assessed by their local specialists. No specific comments can be made about the value of the indirect as opposed to direct ophthalmoscopy as no abnormalities were detected with either technique. It has been suggested that indirect ophthalmoscopy detects more lesions than the direct method, ${ }^{11}$ but in our experience direct ophthalmoscopy through dilated pupils would be sufficient for genetic counselling.

On clinical examination, it was noted that a number of the parents had curious white patches. Hypomelanic macules are the most difficult of the skin signs to interpret as they may be present in normal subjects. Pagon and Cassidy ${ }^{12}$ regarded the presence of two or more macules greater than $1.0 \mathrm{~cm}$ diameter as a positive finding. While the macules may be of any size or shape in TS, those with an ash leaf configuration, which are pale white and smooth in outline, are very distinctive of TS. ${ }^{13}$ One 30 year old woman had an atypical white patch (large, raised, not enhancing under UV light) on the leg. She had non-diagnostic abnormalities on cranial CT and skeletal $x$ rays. Scars from injury or infection did not cause confusion. In the other cases, the white patches were highly atypical of TS. Some appeared as brilliant white areas under ultraviolet light. In addition, curious white or yellow linear streaks were seen on the skin of some subjects. We have seen similar appearances in patients who have been examined under ultraviolet light for reasons other than TS, for example, the early detection of café 
au lait patches in neurofibromatosis. This experience suggests that such findings are artefacts and the negative results on the further clinical and radiological assessment of these subjects supports this conclusion.

The radiological and ultrasound examinations did not diagnose any gene carriers among the parents or sibs investigated, but they did show up some difficulties in interpretation that might arise if these tests were performed routinely.

Abnormalities were found on CT scan in 10 parents. In three cases, very small calcifications were reported in the pineal recess, the midbrain, and the cerebellar gyri, respectively. It is possible that the pineal recess calcification could represent calcification in the upper part of the tentorium. None of these calcified lesions were in typical sites for TS tubers and, while tubers have been observed in various sites within the CNS, they are usually reported in association with subependymal nodules. In the study of CT findings in 60 TS patients by Maki et al ${ }^{14}$ only one patient (aged 12 months) had a cortical or subcortical calcified nodule in the absence of any periventricular nodules. There is one report ${ }^{15}$ of a 17 year old girl with TS with cerebellar calcifications in the dentate nucleus but no supratentorial calcification. The calcification seen in the cerebellum in our patient was indistinguishable from that seen as a normal variant.

The other abnormal findings in the parents consist of cerebral atrophy, ventricular dilatation, and sulcal widening. Once again, it is unusual for such findings to be the only CT abnormalities in TS. In the survey by Maki $e t a l,{ }^{4}$ four scans showed no calcifications. Of these four, two were reported to have cortical atrophy and ventricular dilatation (at ages 10 months and 7 years), one scan showed ventricular dilatation only (at 7 years), and one scan was completely normal (at 35 years). In all of these cases the only reported physical signs were hypomelanic skin macules. Similarly, Martin et $\mathrm{l}^{16}$ reported on the CT findings in 11 cases of TS and found ventricular dilatation as the only abnormality in two patients (aged 2 years and 12 years).

It is therefore unusual for cortical atrophy and ventricular dilatation to be the only signs of TS on CT scan. Such findings may be totally independent of TS and are occasionally seen in otherwise normal subjects. In our opinion it is unlikely that the abnormalities detected are related to TS, and we would assume that these persons are unaffected.

In the study of sibs at $50 \%$ prior risk, two subjects had abnormal CT scans. In both cases, hypodense lesions were present. These lacunae have been reported in several publications on the CT findings in TS, but never as isolated findings in adults with the condition. Their significance must therefore remain doubtful. Similar lacunae may be seen in normal persons. The first subject had a poorly documented history of a seizure in childhood and behaviour problems. His skeletal survey showed an area of periosteal new bone formation in the left tibia, but this was related to an old fracture. In the other case, where hypodense lesions were detected on CT scan, no other abnormalities were found. This person has two children and neither of them has any clinical features of TS. Overall, the evidence suggests that these hypodense lesions are unrelated to TS and we would assume that these subjects are unaffected. The abnormal CT scans of the sibs at low prior risk both showed unusual areas of calcification. In one, a 17 year old girl, there was falx calfication. This is an unusual finding at this age, except in patients with Gorlin's syndrome, but there was no other evidence to suggest that diagnosis. Falx calcification has not been reported in TS and is unlikely to be caused by TS in this girl. In the other case, calcification was reported in the caudate nuclei, but not abutting the ventricular surfaces. Salvolini $e t$ $a l^{17}$ reported the presence of intranuclear tubers in four of their patients. These lesions resembled the subependymal nodules but were located in the basal ganglia away from the ventricular walls. However, in the patient in our study, the calcification is not nodular. There are other causes of basal ganglial calcification, including hypoparathyroidism (excluded in this case) and some dystonic syndromes. Asymptomatic calcification in the basal ganglia is not uncommon in later life $^{18}$ and this may be the explanation. In the absence of other signs of TS, and as the calcification is not nodular, we conclude that this finding is unrelated to TS. This subject has two children who have no clinical evidence of TS.

In the sib study, a definite cyst was observed in the right kidney of a 40 year old subject at $50 \%$ risk, who had no other evidence of TS. The reported incidence of simple renal cysts detected by urography is 1 to $2 \%{ }^{19}$ and therefore the finding of one cyst in this study is not unexpected.

In the survey of skeletal $x$ rays, a considerable number of unusual features were observed, but none of the parents or sibs had any of the classical findings of multiple pseudocysts and periosteal new bone formation. Bone islands were commonly reported, especially in the hands, but not significantly more frequently than in the group of 93 hands $x$ rayed in the Accident and Emergency Department. There were several amorphous sclerotic lesions reported which were not typical of bone islands. There have been only a few studies of bone lesions in TS, but in the survey by Holt and Dickerson ${ }^{20}$ sclerotic lesions were typically evident in the pelvis and vertebrae. Gomez $^{2}$ commented that peripheral lesions can be present and, if present, tend to be diffuse and poorly marginated and have been mistaken for metastases. The lesions observed in the five cases in this study were reasonably well marginated and would not be mistaken for metastases.

Bone abnormalities have not been reported as 
isolated findings in TS patients. In view of the fact that the lesions observed here are so atypical, they are probably incidental findings. This conclusion would be supported if further large studies of the hands in known TS patients failed to show similar lesions.

The three surveys showing lucent areas in the bones are even more difficult to interpret, as pseudocysts are well recognised in TS. None of these lesions resembled the previously described appearances. The cystic lesions, as reported by Holt and Dickerson, ${ }^{20}$ are not punched out areas but seem to be formed by slowly progressive rearrangement of the trabeculae which, in turn, may coalesce to produce a smeared sclerotic appearance around the cystic areas. In none of the $x$ rays in this study showing cystic changes was there any surrounding sclerosis. It seems probable, therefore, that these appearances are unrelated to TS, but it is difficult to be certain without further large studies of TS patients and also of the general population. There is nothing in radiological publications about the incidence of similar appearances in normal subjects.

In summary, therefore, while it is possible that some of the unusual features discovered on the radiological and ultrasound studies performed in these families could represent manifestations of TS, it is more likely that these findings were coincidental, in view of the fact that these features were so atypical and may have alternative explanations.

If one assumes that the unusual findings are coincidental, all the families in this survey with only one affected child represent new mutations. Further evidence to support this conclusion comes from the fact that the 38 families with only one affected member contained 55 apparently unaffected full sibs. If non-penetrance was occurring in a number of these parents, it would be expected that more families with more than one affected child would have occurred. One possible source of error in these families would be non-paternity. The majority of the families, however, were fully blood grouped and half of them were typed for the red cell enzyme and plasma protein polymorphisms used for the linkage study ${ }^{10}$; these analyses provided no evidence for non-paternity.

Two families had two affected and no unaffected children. In one of these families, neither parent had any radiological abnormalities and in the other, one parent had minimal ventricular dilatation reported on CT scan and a sclerotic lesion of the first metacarpal on hand $x$ ray. These findings are probably unrelated to TS and it may be that the recurrence of TS in these families is the result of germline mosaicism, as suggested by Hall and Byers. ${ }^{21}$ One of these families lived within a Bristol and Wessex population of $2 \cdot 8$ million in which we have attempted complete ascertainment of TS cases. This family represented the only recurrence among a total of 73 sibs born to clinically normal parents; 27 of these sibs were born
Table 4 Published reports where clinically normal subjects have transmitted the TS gene.

\begin{tabular}{lll}
\hline Report & \multicolumn{1}{c}{ Affected subjects } & \multicolumn{1}{c}{ Reference } \\
\hline Wilson & Two sibs & Lancet 1978;i:340 \\
Rushton & Child and maternal uncle & J Med Genet 1979;16:32. \\
Lowry & Two sibs & Lancet 1979;i:216 \\
Baraitser & Child and first cousin & J Med Genet 1985;22:29 \\
Flinter & Two sibs & Lancet 1986;ii:1167 \\
Connor & Two half sibs & Lancet 1986;ii:1275 \\
\hline
\end{tabular}

after the affected child, giving a recurrence risk of $3.7 \%$. The numbers on which this figure is based are small and only one other study, that of Bundey and Evans, ${ }^{3}$ quotes the number of unaffected sibs in the families of apparent new mutations. In that survey, there were 61 such families with a total of 137 other children, of whom 58 were born after the affected child. Information could be gathered on only 100 of these 137 children and it is not clear how many were personally examined to confirm their unaffected status. Until further studies are published, it is not possible for a more accurate estimate of the recurrence risk to be made. The numbers of reports where the TS gene has been transmitted by clinically normal parents are few and those that have been published are summarised in table 4 . In view of the paucity of such reports, it may be that the true recurrence risk is nearer $1 \%$, which is the figure that Sampson et $a l^{22}$ quote in clinical practice.

The major conclusion to be drawn from this study is that the value of an extensive radiological investigation of parents and sibs is doubtful and that the most important aspect of the assessment is the clinical examination. If neither parent has any skin or eye signs, it is unlikely that they will have diagnostic abnormalities on radiological investigation. Cassidy $e t$ $a l^{8}$ argue that these investigations should be performed routinely, as in any one family the detection of a gene carrier would alter the recurrence risk from $<5$ to $50 \%$. The results of this study, in keeping with the studies of Fleury $e t a l^{7}$ and Racy $e t a l,{ }^{23}$ would not support such an approach. Many clinicians recommend performing CT scanning in view of the isolated published reports of its value. The major argument against this approach is that considerable problems of interpretation may result. Indeed, in the case of the father in one of our families, the calcification present in the pineal recess had been originally reported as consistent with TS. This was not a view that we shared. On reviewing the $x$ ray films with the neuroradiologist who had first reported on them, he fully agreed that the finding was not typical of TS and suggested that it might represent calcification in the tentorium. These problems of interpretation provide a strong argument for not performing CT scanning routinely.

While a case could be made for CT scanning, the 
value of other investigations is doubtful. There was one subject where only renal ultrasound detected abnormalities (M R Gomez, personal communication), but this has not proved useful in our study. It is, however, a cheap, readily available, and non-invasive test. If renal ultrasound did detect a renal angiomyolipoma, then this would be a significant finding. There is a greater likelihood that it would detect a cyst, as happened in this survey, and then a problem would arise as to the diagnostic significance of the finding. If bilateral polycystic disease is discovered, in the absence of any other cause, then this might be significant, but a considerable dilemma would occur if bilateral single cysts were detected. All these difficulties need to be considered before embarking on this investigation. It seems to us that the frequency with which such problems may arise and the lack of evidence of its usefulness should preclude renal ultrasound from a routine protocol. A similar argument applies to skeletal radiology. In this study, this investigation produced a number of findings which are difficult to interpret. Furthermore, there have been no reports of bone abnormalities as the only sign in TS. There does not, therefore, seem to be any evidence to support the inclusion of this investigation in the routine assessment of family members. Honeycomb lung, usually seen in females, was not seen in any subject. One further investigation, echocardiography, has recently ${ }^{24}$ been shown to detect cardiac rhabdomyomata in patients with TS. Echocardiography was not available to us and was not investigated in this study. If a well established investigation such as cranial CT scanning has not proved useful, then it seems unlikely that this would prove useful either. Furthermore, there is also evidence that the cardiac rhabdomyomas in TS get smaller as the child grows ${ }^{25}$ and hence the chance of detecting these lesions in adults is reduced. The low recurrence risk in those clinically normal suggests that echocardiography may not prove useful.

In summary, therefore, the most important part of carrier detection in parents of a TS child is the clinical examination. Despite the findings of this study, it may still be prudent to include cranial CT scanning for carrier detection. There is sufficient evidence from published reports that it can be useful and it is uncommon to find abnormalities which are incorrectly thought to be signs of TS. Even if only one positive scan were found for each 100 couples, it would have been cost effective because it would clearly alter the recurrence risk for the family concerned. Our two families with normal parents but two affected children will remind those involved in counselling that even when both parents are normal on clinical examination and investigation, there is still a recurrence risk of $<5 \%$. If a parent has a single pathognomonic sign, it is possible that such a person is an gonosomal mosaic, as suggested by Edwards (personal communication). In such cases, the recurrence risk may be considerably less than $50 \%$. We have seen patients with a single ungual fibroma as the only physical sign who have affected sibs and children. This experience leads us to believe that at least some patients with a single pathognomonic feature are not mosaic and we would counsel a $50 \%$ recurrence risk in these situations.

1 Vogt H. Zur Diagnostik der tuberosen sklerose. Z Erforsch Behandl fugendl Schwachsinns 1908;2:1-12.

2 Gome\% MR, ed. Tuberous sclerosis. New York: Raven Press, 1979.

3 Bundey S, Evans K. Tuberous sclerosis: a genetic study. I Neurol Neurosurg Psychiatry 1969;32:591-603.

4 Lagos JC, Gomez MR. Tuberous sclerosis: reappraisal of a clinical entity. Mayo Clin Proc 1967;42:26-49.

5 Wilson J, Carter C. Genetics of tuberous sclerosis. Lancet $1978 ; \mathrm{i}: 340$.

6 Murphy JV, D'Souza BJ, Haughton VM. CT scans and tuberous sclerosis. $\mathcal{F} A M A$ 1976;236:1115.

7 Fleury P, de Groot WP, Delleman JW, et al. Tuberous sclerosis: the incidence of sporadic cases versus familial cases. Brain Dev 1979;2:107-17.

8 Cassidy SB, Pagon RA, Pepin M, Blumhagen JD. Family studies in tuberous sclerosis; evaluation of apparently unaffected parents. $\mathcal{F} A M A$ 1983;248:1302-4.

9 Flinter FA, Neville BGR. Examining the parents of children with tuberous sclerosis. Lancet 1986;ii:1167.

10 Fryer AE, Chalmers A, Connor JM, et al. Evidence that the gene for tuberous sclerosis is on chromosome 9. Lancet 1987; $\mathrm{i}$ : 659-61.

11 Shelton RW. The incidence of ocular lesions in tuberous sclerosis. Ann Ophthalmol 1975;7:771-4. 12 Pagon RA, Cassidy SB. Diagnosis of tuberous sclerosis. $\mathcal{F} A M A$

13 Bundey S. The significance of a white macule on the skin of a child. Dev Med Child Neurol 1970;12:805-6.

14 Maki Y, Enomoto T, Marayuma H, Maekawa K. Computed tomography in tuberous sclerosis. Brain Dev 1979;1:38-48.

15 Winter $\mathrm{J}$. Computed tomography in diagnosis of intracranial tubers versus tubers in tuberous sclerosis. Acta Radiol 1982;23: 337-44.

16 Martin GI, Kaiserman D, Liegler D, Amorosi ED, Nadel H. Computer-assisted cranial tomography in early diagnosis of tuberous sclerosis. $\mathcal{F A M A}$ 1976;235:2323-4.

17 Salvolini V, Pasquini V, Vouge M.CT diagnosis of phakomatoses. f Neuroradiol 1984;11:29-45.

18 Lang A, Marsden D. Children with involuntary movement disorders. In: Gordon N, McKinlay I, eds. Neurologically sick children: treatment and management. Oxford: Blackwell Scientific Publications, 1986.

19 Becker JA, Schneider M. Simple cyst of the kidney. Semin Roentgenol 1975;10:103-11.

20 Holt JF, Dickerson WW. The osseous lesions of tuberous sclerosis. Radiology 1952;58:1-7.

21 Hall JG, Byers PH. Genetics of tuberous sclerosis. Lancet 1987;i:751.

22 Sampson JR, Scahill SJ, Stephenson JBP, Mann L, Connor JM. Genetic aspects of tuberous sclerosis in the west of Scotland. f Med Genet 1989;26:28-31.

23 Racy A, Barakat AY, Cochran WE. Computerized axial tomography in family members of patients with tuberous sclerosis. Clin Pediatr 1978;17:883-5.

24 Gibbs JL. The heart and tuberous sclerosis: an echocardiographic and electrocardiographic study. Br Heart $\mathcal{f}$ 1985;54:596-9.

25 Smith HC, Watson GH, Patel RG, Super M. Cardiac rhabdomyomata in tuberous sclerosis: their course and diagnostic value. Arch Dis Child 1989;64:196-200. 